\title{
Serial recall of two-voice lists: Implications for theories of auditory recency and suffix effects
}

\author{
ROBERT L. GREENE \\ Case Western Reserve University, Cleveland, Ohio
}

\begin{abstract}
Substantial recency effects are found in immediate serial recall of auditory items. These recency effects are greatly reduced when an irrelevant auditory stimulus (a stimulus suffix) is presented. A number of accounts that have been proposed to explain these phenomena assume that auditory items are susceptible to masking or overwriting in memory. Later items overwrite earlier items, leading to an advantage for the last item, unless it is masked by a suffix. This assumption is called into question by evidence that presenting list items in two voices has no beneficial effect in immediate serial recall. In addition, it is shown that suffix effects on both terminal and preterminal list items are influenced by the physical similarity of the suffix to the terminal item and not by the physical similarity of the suffix to preterminal items.
\end{abstract}

In immediate serial recall of auditory items, there is a marked advantage for the last few items (see, e.g., Conrad \& Hull, 1968; Corballis, 1966; Murray, 1966). This large recency effect is generally not found in recall of visually presented items. (The auditory advantage in recall of terminal items is called the modality effect.) Recall of auditory items can be disrupted if an irrelevant speech sound occurs after the last item (see, e.g., Crowder, 1967; Dallett, 1965). This disruption, called the stimulus-suffix effect, is typically greatest on the last few items.

A number of theories have been proposed to account for auditory recency and suffix effects (for reviews, see Crowder, 1976; Greene, 1986; Penney, 1989). There is one assumption that many of these theories sharenamely, that auditory recency and suffix effects result from a common process of interference in memory. (This assumption will be referred to here as the overwriting assumption.) Generally, these theories assume that auditory items enter into a state in which they are easily available to the subject but are vulnerable to interference from subsequent items. As each item is presented, it interferes with earlier items. The last item suffers no such interference and therefore is most easily recalled. However, if a suffix is appended to the list, it will interfere with the last item just as list items interfered with earlier items. The suffix thus reduces the auditory recency effect.

The most prominent theory of this kind is that of Crowder and Morton (1969). These theorists assumed that list items entered into an echoic memory store that they termed precategorical acoustic storage (PAS). Information in this store persisted for at least several seconds and

I would like to thank Theresa Blachly, James Klein, and Halli Shumaker for their help in the making of stimulus tapes and the testing of subjects. Correspondence concerning this article should be addressed to R. L. Greene, Department of Psychology, Case Western Reserve University, Cleveland, $\mathrm{OH} 44106$. could be used in recall. Later items masked earlier items, so that only information about the last item would be available in echoic memory at the time of recall. An auditory suffix would serve as a mask and interfere with information about the last item remaining in echoic memory.

Considerable evidence has been presented against Crowder and Morton's (1969) account. Some of this evidence shows that substantial recency and suffix effects may be found in serial recall even when auditory presentation is not used. For example, lists that are lipread (Campbell \& Dodd, 1980; Greene \& Crowder, 1984; Spoehr \& Corin, 1978) or silently mouthed (Greene, 1989; Greene \& Crowder, 1984, 1986; Nairne \& Walters, 1983) may show recency and suffix effects. Partly as a response to findings such as these, a number of alternative accounts have been proposed. However, several of these accounts (e.g., those of Broadbent \& Broadbent, 1981; Campbell, Dodd, \& Brasher, 1983; Nairne, 1990) make the same overwriting assumption as did Crowder and Morton but differ only by arguing that overwriting happens at a stage more central than echoic memory. For example, Nairne (1990) included an overwriting process in his account of recency and suffix effects: As a result of overwriting, the probability of recall of an event is reduced when the features of that event occur in later stimuli.

The evidence most often cited to support this overwriting assumption comes from studies in which the nature of suffixes has been manipulated. It has been shown that the magnitude of suffix effects is typically a function of the similarity of the suffix to the list items. Suffixes presented in a different voice or a different spatial location from those for the list items are not as effective as suffixes more physically similar to the items (see, e.g., Morton, Crowder, \& Prussin, 1971; Watkins \& Watkins, 1980). If one assumes that interference happens at the featural level, this pattern would be predicted by the overwriting assumption. 
Included in the overwriting assumption is the claim that each list item essentially operates as a suffix on earlier items; thus the principles that underlie suffix effects should also be present in the interference that each item causes earlier items. There is little evidence testing this claim. However, one relevant line of evidence comes from studies of multiple-voice lists. Watkins and Watkins (1980) performed a series of experiments in which lists were read by alternating voices. Subjects received word lists in which a male and female speaker alternated reading the items. According to theories making the overwriting assumption, subjects should be able to recall these lists more easily than lists read in one voice. The alternating voices should lead to a reduction in interference between items in the same way that it leads to a reduction in interference by suffixes. However, this was not found. When subjects were tested for free recall, there was no advantage for dual-voice presentation over single-voice presentation. In fact, in one of the two experiments, there was a small but significant advantage for single-voice presentation at early positions, though there was no difference at later serial positions. Similar results were reported by Mattingly, Studdert-Kennedy, and Magen (1983) and Martin, Mullennix, Pisoni, and Summers (1989). While these results do not rule out the overwriting assumption, they do fail to provide support for it.

In all of these experiments, subjects were allowed to write down list items in any order. Since it has been shown that subjects may use the physical properties of the items to order their output (e.g., Broadbent \& Gregory, 1961) and that probability of recall may be influenced by output order (e.g., Dalezman, 1976), it is possible that subjects in single-voice and multiple-voice conditions may follow greatly different output strategies and that these influence recall level. Watkins and Watkins $(1980$, p. 30) themselves raise the possibility that an advantage for multiple-voice lists over single-voice lists might have been found if they had required subjects to begin recall from the beginning of the list. It is worth noting that some theorists who make the overwriting assumption (e.g., Morton, Marcus, \& Ottley, 1981; Nairne, 1990) explicitly restrict their accounts to serial recall and admit the possibility that other processes account for recency and suffix effects in free recall.

The experiments reported here replicate and extend previous work comparing lists presented in one voice with lists presented in more than one voice. Here, all lists are presented in one or two voices. All subjects were given serial-recall instructions-that is, they were required to write down the items in order. In addition, suffix effects on two-voice lists were examined in Experiments 3 and 4.

\section{EXPERIMENT 1}

In Experiment 1, subjects received taped auditory lists or words read either in one voice or in alternating male and female voices. The subjects were tested for immediate serial (i.e., ordered) recall.

\section{Method}

Subjects. Twenty students from introductory psychology classes participated to fulfill a course requirement.

Materials. Forty-four lists were recorded on a cassette tape. Each list consisted of eight common one-syllable nouns, with each word occurring on only one list. Eleven lists were read by a male experimenter, and 11 were read by a female experimenter. On the remaining lists, the male and female alternated, with the male reading the first item on half of those lists and the female reading the first item on the rest. A second tape was made on which lists presented in the dual-voice condition on the first tape were now read in a single voice and lists in the single-voice condition were read in two voices.

Lists were read at a pace of one item per second. Conditions were randomly mixed, and subjects did not know what condition was being tested until they heard the second word. (The first four lists, two single- and two dual-voice lists, were considered practice and not scored. $)^{1}$

Procedure. Subjects were tested in groups of 3-5 people. After each tape was presented on a cassette player, the experimenter pressed the "Silent Pause" button, and the subjects attempted to recall the words. The subjects were told to write the items in order, without backtracking. They were to draw lines to stand for items they could not recall. The experimenter monitored compliance. Recall was self-paced. After the subjects had recalled the items, the experimenter began the next list until all 44 lists had been presented.

\section{Results and Discussion}

The results are shown in Table 1. Performance is scored both in terms of a position criterion (was an item recalled in the correct position?) and an item criterion (was an item recalled at all?). Under either scoring criterion, there is no advantage for the dual-voice condition but rather an advantage for the single-voice lists. Analyses of variance were performed (using a .05 significance level) separately on the data from the item and position criteria. The analysis using the position criterion showed a significant advantage for the single-voice condition $[F(1,19)=16.32$, $\left.M S_{\mathrm{e}}=4.42\right]$ and a significant effect of serial position $\left[F(7,133)=32.70, M S_{\mathrm{e}}=1,746\right]$. The interaction between condition and position did not approach significance $\left[F(7,133)=1.49, M S_{\mathrm{e}}=5.50, p>.1\right]$. In the analysis using the item criterion, there were significant effects of dual- versus single-voice condition $[F(1,19)=5.33$, $\left.M S_{\mathrm{e}}=5.86\right]$ and serial position $[F(7,133)=17.86$, $M S_{\mathrm{e}}=16.19$ ], as well as a significant interaction between condition and position $\left[F(7,133)=2.32, M S_{\varepsilon}=4.67\right]$. This interaction reflects the fact that the advantage for the single-voice condition was larger at early list positions than at later list positions, where the two conditions led to roughly equivalent levels of recall. This replicates the pattern found by Watkins and Watkins (1980, Experiment 2) and Martin et al. (1989). The reason why this interaction is significant only when recall is scored using the item criterion is not clear. The advantage for dualvoice lists over single-voice lists is greater at each of the eight positions if one uses the position criterion rather than the item criterion. Such a pattern is unlikely to occur by chance ( $p<.05$ by a sign test).

The most important finding is the replication of the advantage for single-voice lists in a situation where recall 
Table 1

Proportions of Items Recalled in Experiments 1-4

\begin{tabular}{|c|c|c|c|c|c|c|c|c|}
\hline \multirow[b]{2}{*}{ Condition } & \multicolumn{8}{|c|}{ Serial Position } \\
\hline & 1 & 2 & 3 & 4 & 5 & 6 & 7 & 8 \\
\hline \multicolumn{9}{|c|}{ Experiment 1} \\
\hline Single-voice (item criterion) & .78 & .50 & .45 & .35 & .39 & .42 & .53 & .68 \\
\hline Dual-voice (item criterion & .64 & .48 & .44 & .33 & .36 & .40 & .52 & .67 \\
\hline Single-voice (position criterion) & .74 & .45 & .33 & .23 & .23 & .24 & .44 & .66 \\
\hline Dual-voice (position criterion) & .59 & .40 & .29 & .19 & .18 & .21 & .41 & .64 \\
\hline \multicolumn{9}{|c|}{ Experiment 2} \\
\hline Single-voice & .98 & .90 & .85 & .81 & .77 & .78 & .78 & .97 \\
\hline Dual-voice & .93 & .83 & .80 & .78 & .73 & .71 & .77 & .90 \\
\hline \multicolumn{9}{|c|}{ Experiment 3} \\
\hline Single-voice (no suffix) & .97 & .88 & .80 & .82 & .75 & .70 & .78 & .97 \\
\hline Single-voice (same-voice suffix) & .92 & .86 & .80 & .80 & .65 & .56 & .55 & .65 \\
\hline Single-voice (different-voice suffix) & .95 & .83 & .76 & .73 & .68 & .61 & .64 & .76 \\
\hline Dual-voice (no suffix) & .91 & .84 & .76 & .75 & .70 & .68 & .72 & .93 \\
\hline Dual-voice (same-voice suffix) & .91 & .81 & .67 & .66 & .62 & .59 & .53 & .59 \\
\hline Dual-voice (different-voice suffix) & .94 & .82 & .74 & .67 & .65 & .60 & .59 & .74 \\
\hline \multicolumn{9}{|c|}{ Experiment 4} \\
\hline Single-voice (no suffix) & .95 & .87 & .79 & .77 & .71 & .67 & .77 & .97 \\
\hline Single-voice (same-voice suffix) & .91 & .81 & .72 & .69 & .60 & .56 & .59 & .68 \\
\hline Single-voice (different-voice suffix) & .91 & .78 & .74 & .70 & .65 & .57 & .62 & .76 \\
\hline Dual-voice (no suffix) & .93 & .81 & .73 & .70 & .69 & .62 & .69 & .95 \\
\hline Dual-voice (same-voice suffix) & .89 & .75 & .67 & .63 & .55 & .50 & .49 & .66 \\
\hline Dual-voice (different-voice suffix) & .91 & .76 & .67 & .65 & .62 & .55 & .56 & .79 \\
\hline
\end{tabular}

output order is controlled. The claim that auditory recency effects result from an interference process where each item overwrites the physical features of the preceding item would be supported if recall of the next-to-last item was much higher in the dual-voice condition than in the singlevoice condition (since the next-to-last item in the dualvoice condition is not followed by a physically similar stimulus). In fact, however, recall of the next-to-last item was slightly (but not significantly) higher in the singlevoice condition than in the dual-voice condition for the item and position scoring criteria (in both cases, $F<1.0$ ).

\section{EXPERIMENT 2}

In the previous experiments (Martin et al., 1989; Mattingly et al., 1983; Watkins \& Watkins, 1980; and Experiment 1 in this study) that were performed to compare the recall of single- and multiple-voice lists, words lists were used. In each case, the words occurred only once on a list, and they were included on only one list.

Greene, Elliott, and Smith (1988) argued that one might not expect to find evidence for overwriting of auditory features when subjects have to recall lists of unique words. They argued that auditory features undergo a process of rapid decay and may not be distinct enough for subjects to use them to recall words. However, when the items come from a constrained set (e.g., digits), subjects should be able to use the fading features to choose between the possible response options. Greene et al. argued that the overwriting account is a viable approach if list items come from a constrained set, but not if lists consist of unique words.

This suggests that, if one wants to find evidence for the overwriting approach, one should use lists composed of items from a constrained set. Therefore, in Experiment 2, the recall lists consisted of digits.

\section{Method}

Subjects. Eighteen students from introductory psychology classes participated to fulfill a course requirement.

Materials. Each list was composed of eight digits from 1 through 9 arranged in a random order. A digit did not occur more than once on a list. As in Experiment 1, 44 lists were constructed, with equal numbers being read in the male voice, in the female voice, in alternating voices (with the male reading the first item), and in alternating voices (with the female reading the first item), all at a 1-sec rate. The first four lists were again not scored. As in Experiment 1, two tapes were recorded to allow counterbalancing of lists with condition (single or dual voice).

Procedure. The procedure was identical to that used in Experiment 1.

\section{Results and Discussion}

The results are shown in Table 1. Since all lists contained digits and required little memory for the identities of items, all scoring used the position criterion. The results resembled those from Experiment 1 (especially when that experiment was scored by the position criterion). There was an advantage for the single-voice condition over the dual-voice condition $\left[F(1,17)=7.65, M S_{\mathrm{e}}=8.64\right]$. There was a main effect of serial position $[F(7,119)=$ $\left.12.45, M S_{c}=7.65\right]$, but position did not interact with condition $\left[F(7,119)=0.86, M S_{\mathrm{e}}=1.93\right]$. 


\section{EXPERIMENT 3}

The primary evidence cited in favor of an overwriting process is the fact that suffix effects are reduced when the suffix is physically dissimilar to the list items (Morton et al., 1971). There is an alternative account for this finding, however-a perceptual-grouping account. Kahneman and Henik (1981) argued that a suffix impairs recall when it is grouped with the list items. Physical similarity influences the suffix effect not by changing the amount of overwriting but rather by influencing the probability that a suffix will be perceived as belonging to the same perceptual group as the list items.

On conventional lists, it is hard to distinguish between overwriting and grouping accounts, because both predict that physical similarity would determine suffix effectiveness. However, the alternating-voice method used in the first two experiments suggests a possible way to contrast these accounts. In Experiment 3, lists were presented in one or two (alternating) voices. Each list was followed by no suffix, by a suffix in the same voice as that which read the last item, or by a suffix in the other voice.

An overwriting account would predict that recall of the last item would be impaired more by a suffix in the same voice than by a suffix in a different voice. To the extent that suffix overwriting occurs at preterminal positions, the next-to-last item should be impaired more by a suffix in the same voice (that is, in a voice different from the one that leads to greatest interference at the last position). On the other hand, if perceptual grouping underlies the suffix effect, then the most effective suffix on all items should be the one that continues the alternating pattern found on the list-that is, the suffix read in a voice different from that for the last item. ${ }^{2}$

\section{Method}

Subjects. Twenty-four students from introductory psychology classes participated to fulfill a course requirement.

Materials. Sixty-six lists were created. As in Experiment 2, each list was composed of eight nonrepeating digits from the set 1-9. Lists were read either in one voice (a male or a female voice) or in alternating voices (with either the female or the male voice starting). Lists could be followed by silence (no suffix), by a suffix in the same voice as the voice that read the last item (same-voice suffix condition), or by a suffix in the other voice (different-voice suffix condition). The suffix was the word end and was read $1 \mathrm{sec}$ after the last item. In short, there were six conditions (single or dual voice, crossed with three suffix conditions). The conditions were intermixed randomly in a session, with the constraint that each occur once in the first six lists. (The first six lists were considered practice and were not scored.) Six different tapes were constructed so that each list was used equally in each condition. In other respects, the tapes resembled those used in the first two experiments.

Procedure. The subjects were tested alone or in groups of 2-3 people. The procedure was otherwise identical to that used in the previous experiments.

\section{Results and Discussion}

The results are shown in Table 1. When the single-voice lists are examined, the results are consistent with previ- ous results (e.g., those in Morton et al., 1971). There is a marked recency effect in the no-suffix condition. This recency effect is reduced by the presence of a suffix, with the suffix effect being greater for a suffix in the same voice as the voice for the list items than it was for a suffix in the opposite voice.

Replicating the results of the first two experiments, the recall of dual-voice lists was lower than the recall of single-voice lists. Contrary to the prediction arising from the perceptual-grouping account, recall of the terminal item was still impaired more by an item in the same voice than by an item in a different voice.

A three-way analysis of variance was carried out using the repeated-measures variables of single- or dual-voice condition, serial position, and suffix. There were significant main effects of voice condition $[F(1,23)=7.49$, $\left.M S_{\mathrm{e}}=5.76\right]$, serial position $\left[F(7,161)=33.27, M S_{\mathrm{e}}=\right.$ $4.71]$, and suffix condition $\left[F(2,46)=25.76, M S_{e}=\right.$ 4.53]. However, the only significant interaction occurred between position and suffix condition $[F(14,322)=$ $\left.10.80, M S_{\mathrm{e}}=1.34\right]$. That none of the interactions with voice condition approached significance reflected the fact that the single- and dual-voice conditions showed similar patterns.

Two additional tests carried out only on the dual-voice data are worth mentioning. In the first test, recall of the last item in the same-voice suffix condition was compared with recall of the last item in the different-voice suffix condition. This test confirmed that the suffix effect on the terminal position of dual-voice lists was reduced when the suffix was in a different voice $\left[F(1,23)=22.18, M S_{e}=\right.$ 1.22]. A second test was carried out on the next-to-last position from these two conditions. Remember that the terms same-voice and different-voice refer to the relationship between the suffix and the last item; the next-to-last item on dual-voice lists was in the same voice as was the suffix in the different-voice condition. Recall was higher at the seventh position in the different-voice suffix condition than in the same-voice suffix condition $[F(1,23)=$ $\left.5.01, M S_{\mathrm{e}}=0.62\right]$. These data from the seventh position on dual-voice lists suggest that the magnitude of suffix effects on preterminal items is influenced by the physical similarity of the suffix to the terminal item, not by the similarity of the suffix to preterminal items.

\section{EXPERIMENT 4}

The results of Experiment 3 suggest that the magnitude of suffix effects on both terminal and preterminal positions of dual-voice lists reflects the similarity of the suffix to the terminal item. In Experiment 4, this finding was extended with a different arrangement of voices. On dualvoice lists, one voice read the first seven items, and the other voice read only the last item.

\footnotetext{
Method

Subjects. Twenty-four students from introductory psychology classes participated to fulfill a course requirement.
} 
Procedure. The only difference between Experiments 3 and 4 was that, in Experiment 4, on dual-voice lists, one voice read the first seven items, and the other voice read the last item.

\section{Results and Discussion}

The results are shown in Table 1. The important conclusion is that these results replicate the major findings of Experiment 3. There was again an overall advantage for single-voice lists over dual-voice lists. There were significant main effects of single- or dual-voice condition $[F(1,23)$ $\left.=8.63, M S_{e}=4.70\right]$, serial position $[F(7,161)=33.62$, $\left.M S_{e}=5.57\right]$, and suffix condition $[F(2,46)=28.46$, $\left.M S_{c}=4.92\right]$. The only significant interaction was again the expected interaction between position and suffix condition $\left[F(14,322)=6.70, M S_{e}=1.23\right]$, which merely reflects the often documented finding that suffix effects are larger at the terminal list position than at earlier positions.

Several analyses were carried out to examine the nature of the suffix effects found on dual-voice lists. Recall of the terminal item was lower in the same-voice suffix condition than in the different-voice suffix condition $\left[F(1,23)=10.71, M S_{e}=1.75\right]$. As in Experiment 3, the preterminal suffix effect shows a similar pattern, with recall of preterminal items being more impaired when the suffix was in the same voice as that for the terminal item than when the suffix was in the same voice as that for preterminal items. Since all of the preterminal items were read in the same voice, all seven preterminal positions can be added to form an overall score for preterminalitem recall. This score is significantly lower for the samevoice suffix condition, in which the suffix matched the terminal item, than for the different-voice suffix condition $\left[F(1,23)=6.24, M S_{\mathrm{e}}=1.28\right]$.

\section{GENERAL DISCUSSION}

There are several general findings from these experiments. The first is that recall was consistently higher when all the items were in a single voice than when they were presented in the dual-voice condition. A second general finding from Experiments 3 and 4 is that suffix effects on both terminal and preterminal items reflect the physical similarity of the terminal item to the suffix.

\section{Basis of the Single-Voice Advantage in Recall}

These experiments do not indicate why recall of singlevoice lists was superior to recall of dual-voice lists. Martin et al. (1989) suggested that a single-voice advantage could result from impaired perceptual processing of multiplevoice lists. They argued that perception of the stimuli becomes more difficult when the speaker's voice is varied and that the increased effort that subjects spend perceiving the items leaves fewer resources for rehearsing the items. In their experiments, Martin et al. had either a single speaker read all the items on a 10-word list or a different speaker read each item. They found a small advantage for single-voice lists, but this difference was present only at the first few serial positions. This pattern would indeed be consistent with an encoding deficit operating on multiple-voice lists.

However, it appears unlikely that Martin et al.'s explanation would be satisfactory for the results presented here. With the exception of the item analysis in Experiment 1 , the single-voice advantage found here extended across all serial positions, a finding incompatible with an account implicating rehearsal processes. Rather than compare lists read in 1 voice with lists read in 10 voices, the experiments reported here compared single-voice lists with dual-voice lists, with the 2 voices occurring in a very predictable fashion. One would think that perceptual difficulties should be minimized by reducing the number of voices and making their occurrence highly predictable. Also, in Experiments 2-4, the list items were all digits. The use of such a small, constrained stimulus set should reduce perceptual difficulty. (Indeed, it was in Experiment 1 , in which sets of words were used, that the results most resembled those found by Martin et al., 1989.)

An interesting possibility is suggested by findings reported by Tulving and Colotla (1970). Those investigators presented lists visually in one or more languages. Lists presented in more than one language were not recalled as well as lists presented in a single language. Tulving and Colotla attributed this effect to organizational and retrieval factors. They suggested that, when items are presented in a single language, subjects are free to organize the items in whatever way would lead to maximal recall. However, when items are presented in more than one language, subjects tend to use language to organize the list. This language-based organizational scheme may not be optimal and thus may lead to poorer recall.

One could apply a similar explanation here. It has been shown that subjects use input voice to organize stimulus input (Broadbent \& Gregory, 1961). If subjects are using input voice to organize the items on dual-voice lists, they may be adopting an organizational scheme that is not as effective as that used on single-voice lists. For example, if subjects chunk the dual-voice lists in Experiments 1-3 into two groups defined by input voice, the alternating nature of the organization may interfere with the need to recall all eight items in order. This sort of organizational account could apply to all serial positions and could thus explain why the single-voice advantage is found here throughout the list.

\section{Role of Overwriting in \\ Auditory Recency Effects}

A common explanation for auditory recency effects is that they reflect an interference or overwriting process. Each item overwrites the physical features of previous items. Since the last item does not receive overwriting, it is recalled much better than other items. Such accounts (e.g., Broadbent \& Broadbent, 1981; Campbell et al., 1983; Crowder \& Morton, 1969; Nairne, 1990) base this overwriting assumption on evidence that, when the last 
item is followed by a suffix, recall of the last item is a function of the physical similarity between the suffix and the list items.

The overwriting assumption would get strong support if it were found that lists presented in multiple voices were recalled better than single-voice lists. However, the results from these experiments, in addition to previous work (Martin et al., 1989; Mattingly et al., 1983; Watkins \& Watkins, 1980), do not offer such support. In fact, in the four experiments reported here, it was found that recall of single-voice lists was consistently higher than recall of dual-voice lists.

Although the results found here do not offer support for the overwriting assumption, they do not present a strong challenge to it either. It is possible that whatever the process that benefits recall of single-voice lists may be, it is powerful enough to counteract the advantages of reduced overwriting on dual-voice lists. Such a proposal would seem to predict that the single-voice advantage should be smaller at the seventh position than at the previous positions in that voice. (On dual-voice lists, the seventh item is not being followed by another item in that voice; therefore, it should show a benefit from lack of overwriting that most decreases the benefits caused by single-voice presentation.) Analyses were done to test this prediction. Analyses were performed to compare the difference between single- and dual-voice conditions on the seventh and fifth positions in Experiment 1 (using both the item and position criteria), Experiment 2, and Experiment 3 (using the no-suffix conditions), as well as on the seventh and sixth positions in Experiment 4 (using the nosuffix condition). This prediction was not supported in any of the analyses (in each case, $F<1.0$ ). Even so, however, these null findings are not sufficient to present a fundamental challenge to the overwriting approach.

Although the results presented here should not be seen as contradicting the overwriting assumption, they illustrate the lack of evidence to support this approach as an account of auditory recency effects. Evidence for overwriting tends to come exclusively from findings that stimulus suffixes cause more interference when they physically resemble list items than when they do not. However, this generalization does not always hold (see, e.g., Greene \& Samuel, 1986; Morton et al., 1981). Moreover, there is no evidence either supporting or refuting the claim that auditory recency effects result from items overwriting earlier items.

Although the overwriting account may still be viable, it should be worthwhile to consider theories that use other mechanisms to explain auditory recency effects (e.g., the use of temporal information in retrieval; see Glenberg, 1987; Glenberg \& Swanson, 1986). Such accounts appear to be more consistent with the present data, although the predictions they make for these experiments are not as clear.

\section{Basis of Suffix Effects}

Considerable evidence has been developed in recent years which shows that a suffix has multiple effects. Suffix effects on preterminal items can be experimentally dissociated from suffix effects on the terminal item of a list (see, e.g., Baddeley \& Hull, 1979; Balota \& Engle, 1981; Greenberg \& Engle, 1983; Penney, 1985). Although countless theories have been proposed to explain the suffix effect on the terminal item, less attention has been devoted to explaining the basis of suffix effects on preterminal items.

Experiments 3 and 4 provide one clue for the nature of preterminal suffix effects: The magnitude of preterminal suffix effects is in part determined by the physical similarity of the suffix to the terminal item and not by the similarity of the suffix to preterminal items. This raises the possibility that the suffix does not affect recall of preterminal items directly but rather that preterminal suffix effects result from the negative effect that suffixes have on recall of terminal items.

How could such a process occur? There is considerable evidence that serial lists may be stored in the form of one or more chunks, and that access to one chunk leads to a high probability of recall of all the items in that chunk (Johnson, 1972). In the absence of a suffix, the last item is very easy to recall. People have a very accurate source of information about the last item. This information should not only allow them to recall the last item correctly but may also allow them access to chunks that contain nearby items. Thus, having a very accurate representation of the last item may assist recall of other items. When a suffix occurs, it impairs this representation of the last item. This impairment leads to a decrease in recall not only for the last item but indirectly for other items as well. If the suffix is not in the same voice as the list items, this lessens its effect on the last item and thereby reduces its indirect effect on preterminal items as well.

The experiments reported here provide little information about how the suffix interferes with recall of the last item, beyond raising doubts about the grouping account. Indeed, Experiments 3 and 4 merely show that suffix effects are reduced when the suffix is presented in a different voice from that of the last item. However, these experiments do provide evidence regarding the basis of preterminal suffix effects: These effects appear to be an indirect result of the suffix's direct effect on recall of the last item.

There is one piece of evidence that may appear to contradict this view. Engle (1980) performed an experiment in which lists were presented auditorily. Suffixes were presented after some of the lists. In one condition, Engle showed the subjects the last item visually after the suffix had been presented. Even though subjects in this condition thus always knew the identity of the last item, this did not reduce the magnitude of the suffix effect on preterminal items.

Further research will be needed to reconcile the present results with those of Engle (1980). However, one possibility does present itself. Showing the subject the last item would not necessarily allow subjects to retrieve the episodic trace of the last item. (This is analogous to the way in which one can be told by others that one has had a cer- 
tain experience without necessarily remembering that experience oneself.) Being told what the last item was may not help one retrieve other items. However, remembering the last item-that is, retrieving the episodic trace of the last item-may help one retrieve the traces of the other list items. According to this proposal, preterminal suffix effects are an indirect result of the fact that suffixes make it harder to retrieve the trace of the last item.

\section{REFERENCES}

Baddeley, A., Hull, A. (1979). Prefix and suffix effects: Do they have a common basis? Journal of Verbal Learning \& Verbal Behavior, 18, 129-140.

Balota, D. A., \& ENGLE, R. W. (1981). Structural and strategic factors in the stimulus suffix effect. Joumal of Verbal Learning \& Verbal Behavior, 20, 346-357.

Broadbent, D. E., \& Broadbent, M. H. P. (1981). Recency effects in visual memory. Quarterly Journal of Experimental Psychology, 33A, $1-15$.

Broadbent, D. E., \& Gregory, M. (1961). On the recall of stimuli presented alternately to two sense-organs. Quarterly Journal of Experimental Psychology, 13, 103-109.

CAMPBell, R., \& DoDD, B. (1980). Hearing by eye. Quarterly Journal of Experimental Psychology, 32, 85-99.

Campbell, R., Dodd, B., \& Brasher, J. (1983). The sources of visual recency: Movement and language in serial recall. Quarterly Journal of Experimental Psychology, 35A, 571-587.

Conrad, R., HUlL, A. J. (1968). Input modality and the serial position curve in short-term memory. Psychonomic Science, 10, 135-136.

CoRpallis, M. C. (1966). Rehearsal and decay in immediate recall of visually and aurally presented items. Canadian Journal of Psychology, 20, 43-51.

Crowder, R. G. (1967). Prefix effects in immediate memory. Canadian Journal of Psychology, 21, 450-461.

Crowder, R. G. (1976). Principles of learning and memory. Hillsdale, NJ: Erlbaum.

Crowder, R. G., \& Morton, J. (1969). Precategorical acoustic storage (PAS). Perception \& Psychophysics, 5, 365-373.

Dalezman, J. J. (1976). Effects of output order on inmediate, delayed, and final recall performance. Journal of Experimental Psychology; Human Learning \& Memory, 2, 597-608.

DalletT, K. M. (1965). "Primary memory": The effects of redundancy upon digit repetition. Psychonomic Science, 3, 237-238.

ENGLE, R. W. (1980). The suffix effect: How many positions are involved? Memory \& Cognition, 8, 247-252.

GLENBERG, A. M. (1987). Temporal context and recency. In D. S. Gorfein \& R. R. Hoffman (Eds.), Memory and Learning: The Ebbinghaus Centennial Conference (pp. 173-190). Hillsdale, NJ: Erlbaum.

Glengerg, A. M., \& Swanson, N. G. (1986). A temporal distinctiveness theory of recency and modality effects. Journal of Experimental Psychology: Learning, Memory, \& Cognition, 12, 3-15.

Greenberg, S. N., \& ENGLE, R. W. (1983). Voice change in the stimulus suffix effect: Are the effects structural or strategic? Memory \& Cognition, 11, 551-556.

GREENE, R. L. (1986). Sources of recency effects in free recall. Psychological Bulletin, 99, 221-228.

GREENE, R. L. (1989). Immediate serial recall of mixed-modality lists. Journal of Experimental Psychology: Learning, Memory, \& Cognition, 15, 266-274.

Greene, R. L., \& Crowder, R. G. (1984). Modality and suffix effects in the absence of auditory stimulation. Journal of Verbal Leaming \& Verbal Behavior, 23, 371-382.

Greene, R. L., \& Crowder, R. G. (1986). Recency effects in delayed recall of mouthed stimuli. Memory \& Cognition, 14, 355-360.

Greene, R. L., Elliott, C. L., \& SMith, M. D. (1988). When do interleaved suffixes improve recall? Journal of Memory \& Language, 27, 560-571.
Greene, R. L., \& Samuel, A. G. (1986). Recency and suffix effects in serial recall of musical stimuli. Journal of Experimental Psychology: Learning, Memory, \& Cognition, 12, 517-524.

JohNSON, N. F. (1972). Organization and the concept of a memory code. In A. W. Melton \& E. Martin (Eds.), Coding processes in human memory (pp. 125-159). Washington, DC: Winston.

Kahneman, D., Henik, A. (1981). Perceptual organization and attention. In M. Kubovy \& J. Pomerantz (Eds.), Perceptual organization (pp. 181-212). Hillsdale, NJ: Erlbaum.

Martin, C. S., Mullennix, J. W., Pisoni, D. B., \& Summers, W. V. (1989). Effects of talker variability on recall of spoken word lists. Journal of Experimental Psychology: Learning, Memory, \& Cognition, 15, 676-684.

Mattingly, I. G., Studdert-Kennedy, M., Magen, H. (1983). Phonological short-term memory preserves phonetic detail. Journal of the Acoustical Society of America, 73, S4.

Morton, J., Crowder, R. G., \& Prussin, H. A. (1971). Experiments with the stimulus suffix effect. Journal of Experimental Psychology, 91, 169-190.

Morton, J., MArcus, S. M., \& OtTley, P. (1981). The acoustic correlates of "speechlike": A use of the suffix effect. Joumal of Experimental Psychology: General, 110, 568-593.

MURRAY, D. J. (1966). Vocalization-at-presentation and immediate recall, with varying recall methods. Quarterly Joumal of Experimental Psychology, 18, 9-18.

NaIRNe, J. S. (1990). A feature model of immediate memory. Memory \& Cognition, 18, 251-269.

NAIRNE, J. S., WALTERS, V. L. (1983). Silent mouthing produces modality- and suffix-like effects. Joumal of Verbal Learning \& Verbal Behavior, 22, 475-483.

PENNEY, C. G. (1985). Elimination of the suffix effect on preterminal list items with unpredictable list length: Evidence for a dual model of suffix effects. Journal of Experimental Psychology: Learning, Memory, \& Cognition, 11, 229-247.

PenNey, C. G. (1989). Modality effects and the structure of short-term verbal memory. Memory \& Cognition, 17, 398-422.

SPOEHr, K. T., \& CORIN, W. J. (1978). The stimulus suffix effect as a memory coding phenomenon. Memory \& Cognition, 6, 583-589.

TulviNG, E., \& COLOTlA, V. A. (1970). Free recall of trilingual lists. Cognitive Psychology, 1, 86-98.

WATKINS, O. C., \& WATKINS, M. J. (1980). Echoic memory and voice quality: Recency recall is not enhanced by varying presentation voice. Memory \& Cognition, 8, 26-30.

\section{NOTES}

1. The use of tape-recorded speech, as opposed to synthesized speech, raises the possibility that recall may be being influenced by subtle differences in intonation across conditions. Although no evidence has been reported that subtle intonational changes can influence recency or suffix effects, several precautions were taken with the tapes used in all of the experiments reported here. The speakers were told to maintain a level voice and to re-record any lists where this was not done. The experimenter and two people who were blind to the purposes of the study listened to all the tapes twice; no intonation changes were noticed. Analyses were performed separately on each tape used in each experiment, since a random intonational change would not be expected to recur on a second tape. No differences were found.

2 . It has often been difficult to specify grouping objectively. The intuition that, on dual-voice lists, the suffix would be more likely to be grouped with the list on different-voice suffix lists than on same-voice suffix lists was tested using 12 additional subjects, each of whom listened to one of the six tapes. They were asked to indicate the lists that they felt the suffix "belonged with." All subjects indicated that this grouping of the suffix with the list occurred more often in the different-voice suffix condition than in the same-voice suffix condition.

(Manuscript received April 16, 1990; revision accepted for publication July 18, 1990.) 